\title{
Crop cover reconstruction and its effects on sediment retention in the Tibetan Plateau for 1900-2000
}

\author{
LI Shicheng ${ }^{1,2,3}$, "WANG Zhaofeng ${ }^{1},{ }^{*}$ ZHANG Yili ${ }^{1,2,4}$ \\ 1. Key Laboratory of Land Surface Pattern and Simulation, Institute of Geographic Sciences and Natural \\ Resources Research (IGSNRR), CAS, Beijing 100101, China; \\ 2. University of Chinese Academy of Sciences, Beijing 100101, China; \\ 3. School of Public Administration, China University of Geosciences, Wuhan 430074, China; \\ 4. CAS Center for Excellence in Tibetan Plateau Earth Sciences, Beijing 100101, China
}

\begin{abstract}
Geographically explicit historical land use and land cover datasets are increasingly required in studies of climatic and ecological effects of human activities. In this study, using historical population data as a proxy, the provincial cropland areas of Qinghai province and the Tibet Autonomous Region (TAR) for 1900, 1930, and 1950 were estimated. The cropland areas of Qinghai and the TAR for 1980 and 2000 were obtained from published statistical data with revisions. Using a land suitability for cultivation model, the provincial cropland areas for the 20th century were converted into crop cover datasets with a resolution of $1 \times 1 \mathrm{~km}$. Finally, changes of sediment retention due to crop cover change were assessed using the sediment delivery ratio module of the Integrated Valuation of Ecosystem Services and Trade-offs (InVEST) model (version 3.3.1). There were two main results. (1) For 1950-1980 the fractional cropland area increased from $0.32 \%$ to $0.48 \%$ and land use clearly intensified in the Tibetan Plateau (TP), especially in the Yellow River-Huangshui River Valley (YHRV) and the midstream of the Yarlung Zangbo River and its two tributaries valley (YRTT). For other periods of the 20th century, stability was the main trend. (2) For 1950-1980, sediment export increased rapidly in the Minhe autonomous county of the YHRV, and in the Nianchu River and Lhasa River basins of the YRTT, which means that sediment retention clearly decreased in these regions over this period. The results of this assessment provide scientific support for conservation planning, development planning, or restoration activities.
\end{abstract}

Keywords: cropland reconstruction; ecosystem services; InVEST model; the 20th century; Qinghai province; the Tibet Autonomous Region

Received: 2016-11-05 Accepted: 2017-02-06

Foundation: Strategic Priority Research Program of the Chinese Academy of Sciences, No.XDB03030500; National Natural Science Foundation of China, No.41371120; The Key Foundation Project of Basic Work of the Ministry of Science and Technology of China, No.2012FY111400

Author: Li Shicheng (1989-), PhD, specialized in historical land use and cover change reconstruction and its ecological effects assessment. E-mail: lisc.10s@igsnrr.ac.cn; lisc@cug.edu.cn

*Corresponding author: Zhang Yili and Wang Zhaofeng. E-mail: zhangyl@igsnrr.ac.cn; wangzf@igsnrr.ac.cn 


\section{Introduction}

Human land use activities have dramatically altered the Earth's surface, with serious consequences for environmental systems (Ellis et al., 2013; Foley et al., 2005; Future Earth, 2014). Many studies have undertaken historical land use and cover change (LUCC) reconstructions to consider historical LUCC effects (De Brue and Verstraeten, 2014; Gaillard et al., 2010; Sturck et al., 2015; Zorrilla-Miras et al., 2014). An understanding of anthropogenic land use activities and their ecological effects over long time periods will enable us to better manage human-nature relationships and provide governments with more scientific support when deciding on sustainable development policies.

In the historical LUCC reconstruction field, there are many representative historical land use datasets, including the History Database of the Global Environment (HYDE) (Klein Goldewijk et al., 2011), global land use dataset of the Center for Sustainability and the Global Environment (SAGE) (Ramankutty and Foley, 1999), and Kaplan and Krumhardt (KK10) dataset (Kaplan et al., 2011). These datasets have been widely used to assess the effects of land use change on climate change and ecosystem services over long time periods (Jantz et al., 2015; Simmons and Matthews, 2016; Smith et al., 2016). The reconstruction methods used to develop these datasets have been followed and revised by many regional studies (Dias et al., 2016; He et al., 2015; Jin et al., 2016; Leite et al., 2012; Li et al., 2016; Yang et al., 2016).

Although these studies have made substantial contributions to our understanding, there is still much to learn (Klein Goldewijk and Verburg, 2013; Miao et al., 2013; Miao et al., 2016). For example, the spatial and temporal resolutions of these datasets are coarse, which reduce their potential for application in the assessment of ecological effects (De Brue and Verstraeten, 2014). Some studies have indicated that these datasets have captured the general patterns of cropland change over history, and should only be used for continental-to-global scale analysis and modeling (He et al., 2013; Li et al., 2010; Zhang et al., 2013). As a result, many regional to local scale reconstructions have been conducted (Wei et al., 2016; Ye et al., 2009; Ye et al., 2015).

As the highest and most extensive highland in the world, the Tibetan Plateau (TP) has a distinct natural environment (Zhang et al., 2002), with a global impact. Many major Asian rivers originate from this region, providing water for nearly $40 \%$ of the world's population. It is also a global hotspot for biodiversity conservation. It is widely acknowledged that environmental conditions in the region have changed significantly in the last century due to climate change and human activities, including a loss of biodiversity (Newbold et al., 2015), grassland degradation (Lehnert et al., 2016; Sun et al., 2012), and a decrease in water supply (Pan et al., 2015). Consequently, environmental changes in the TP have generated great public and scientific interest in recent years. However, most land use and cover related studies in the TP only cover the period since the 1970s when satellite-based data is available (Cui and Graf, 2009). There are few historical reconstruction studies because historical records are difficult to obtain and interpret, with only a few initial studies available (Li et al., 2015; Luo et al., 2014; Ryavec, 2001; Wang et al., 2015). There have also been few studies concerning the effects of historical crop cover changes on ecosystem services in this remote region of China. 
Therefore, the objectives of this study were to reconstruct crop cover over the 20th century and assess the effects of crop cover change on sediment retention services in the TP. Based on historical population data and cropland statistical data, the provincial cropland area of Qinghai and the Tibet Autonomous Region (TAR) for 1900, 1930, 1950, 1980, and 2000 was estimated, and then allocated into $1 \times 1 \mathrm{~km}$ grid cells using a land suitability for cultivation model. We then used the Integrated Valuation of Ecosystem Services and Trade-offs (InVEST) model to assess the effects of crop cover change on sediment retention services for 1900-2000. Finally, we considered the uncertainties and prospects of this study.

\section{Study area}

Because population and cropland area data for the TP are political region-based data, so the administrative-level TP, i.e., Qinghai province and the TAR, are selected as the study area (Figure 1). The land area of the two provinces is $122.84 \times 10^{4}$ and $72.10 \times 10^{4} \mathrm{~km}^{2}$, respectively. Most regions of the two provinces are covered by alpine meadows and alpine grassland ecosystems. There is little cropland area, which is mainly distributed in the Yellow River-Huangshui River Valley (YHRV) of Qinghai province, and the midstream of the Yarlung Zangbo River and its two tributaries valley (YRTT: the two tributaries are the Lhasa and the Nianchu rivers) of the TAR. Based on China's Land-Use/cover Datasets (CLUDs) in 2010 , the cropland area of the two provinces was determined to be about $0.30 \%$ and $0.85 \%$ respectively (Liu et al., 2014b).

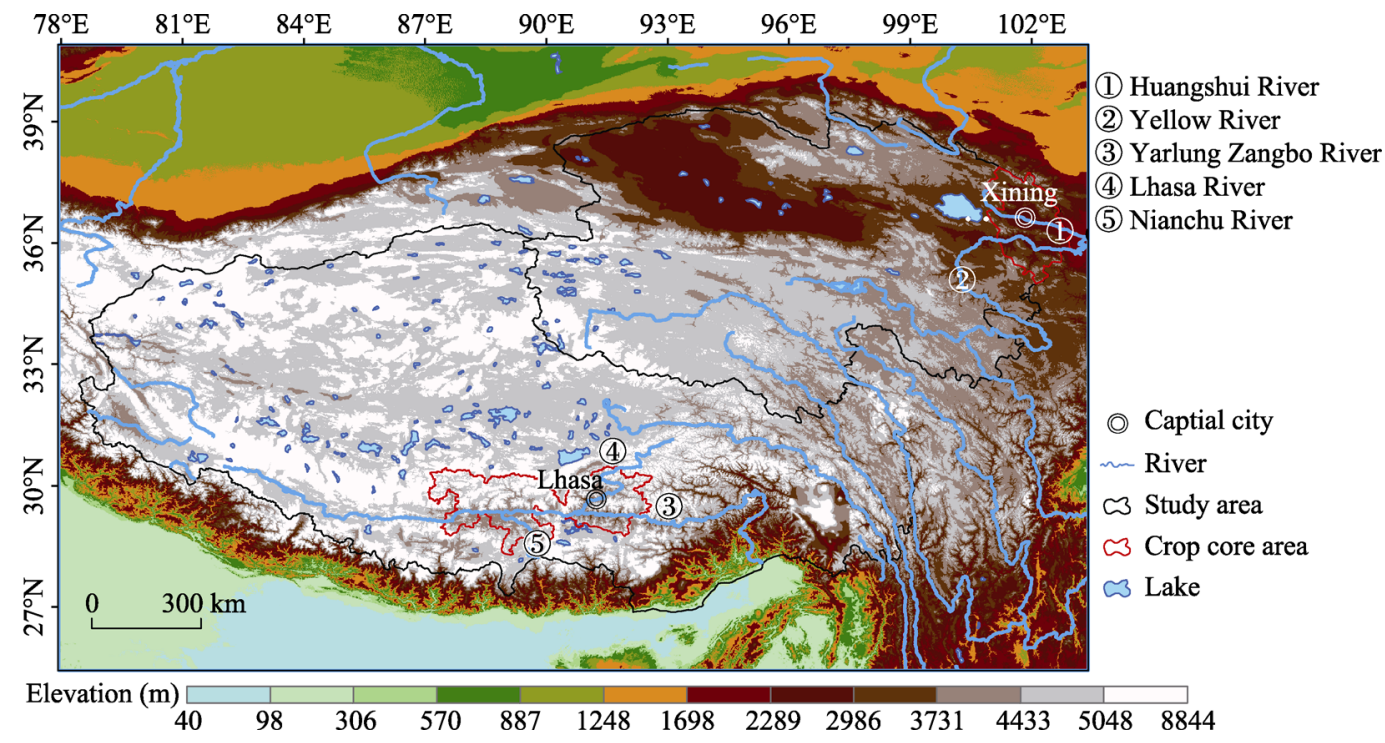

Figure 1 Location of the study area. The two red polygons are the main crop distribution areas in the Tibetan Plateau (TP). The right-top polygon is the Yellow-Huangshui River valley (YHRV), and the middle-bottom polygon is the midstream Yarlung Zangbo River and its two tributaries valley in Tibet Autonomous Region (YRTT).

In this study, following the method of Li et al. (2015), the crop cover of the TP for 1900, 1930, 1950, 1980, and 2000 was reconstructed and their effects on sediment retention services were assessed based on the InVEST model, by focusing on two typical regions: the YHRV and YRTT. 


\section{Data and methods}

\subsection{Estimation of cropland area}

Utilizing the method of Li et al. (2015), the cropland area of Qinghai province and the TAR over the 20th century was estimated. In brief, for 1900, 1930, and 1950, the cropland area was estimated based on the assumption that the per capita cropland area remained constant for the first half of the 20th century. The per capita cropland area of 1953 was determined from cropland area records and a yield inventory (Feng et al., 2005), and historical population data were obtained from Cao and Ge (2001) (Table 1). For 1980, it is believed that the statistical cropland area data was underestimated (Frolking et al., 2002; Liu et al., 2005), and therefore revision was done employing grain yields (Feng et al., 2005). For 2000, existing statistical cropland area data was used.

Table 1 Population of Qinghai province and the Tibet Autonomous Region (TAR) for 1880, 1910, and 1953 (Cao and Ge, 2001) $\left(10^{4}\right.$ person)

\begin{tabular}{lccc}
\hline Province name & 1880 & 1910 & 1953 \\
\hline Qinghai province & 32.9 & 34.4 & 36.7 \\
Tibet Autonomous Region & 127 & 131.2 & 137.4 \\
\hline
\end{tabular}

\subsection{Crop cover reconstruction}

The provincial cropland area cannot be used directly by ecological models. Therefore, the provincial cropland areas were converted into geographically explicit cropland datasets following the model developed by Li et al. (2015). In general, the model consists of the following three steps.

(1) Normalization of land suitability for cultivation factors, including altitude and slope, using Eqs. (1) and (2):

$$
\begin{aligned}
& D^{\prime}\left(i, k_{n}\right)=\frac{\operatorname{Max}\left[D\left(i, k_{n}\right)\right]-D\left(i, k_{n}\right)}{\operatorname{Max}\left[D\left(i, k_{n}\right)\right]} \\
& S^{\prime}\left(i, k_{n}\right)=\frac{\operatorname{Max}\left[S\left(i, k_{n}\right)\right]-S\left(i, k_{n}\right)}{\operatorname{Max}\left[S\left(i, k_{n}\right)\right]}
\end{aligned}
$$

where $D^{\prime}\left(i, k_{n}\right)$ represents the altitude-related cultivation suitability of grid $i$ in province $k_{n}$, $D\left(i, k_{n}\right)$ represents the altitude of grid $i$ in province $k_{n}, S^{\prime}\left(i, k_{n}\right)$ represents slope-related cultivation suitability of gird $i$ in province $k_{n}$, and $S\left(i, k_{n}\right)$ represents the slope of grid $i$ in province $k_{n}$.

(2) Calculation of the suitability of land for cultivation, using Eq. (3):

$$
W_{\text {suit }}\left(i, k_{n}\right)=D^{\prime}\left(i, k_{n}\right) \times S^{\prime}\left(i, k_{n}\right) \times W_{\text {crop }}\left(i, k_{n}\right)
$$

where $W_{\text {suit }}\left(i, k_{n}\right)$ denotes the suitability of land for cultivation of grid $i$ in province $k_{n}$, and $W_{\text {crop }}\left(i, k_{n}\right)$ denotes the potential maximum extent of cropland, which was acquired using satellite-based crop cover data (Liu et al., 2014b).

(3) Allocation of the provincial cropland area into $1 \times 1 \mathrm{~km}$ grids, using Eq. (4): 


$$
\operatorname{Crop}(i, t)=\operatorname{area}\left(k_{n}, t\right) \times \frac{W_{\text {suit }}\left(i, k_{n}\right)}{\sum_{i}^{k_{n}} W_{\text {suit }}\left(i, k_{n}\right)} / \operatorname{gridarea}(i)
$$

where $\operatorname{Crop}(i, t)$ is the cropland area of grid $i$ in year $t$, area $\left(k_{n}, t\right)$ is the cropland area of province $k_{n}$ in year $t$, and gridarea $(i)$ is the land area of each grid.

\subsection{Assessment of changes in sediment retention}

The crop cover datasets were used to assess the effects of crop cover change on changes in sediment retention services, focusing on the YHRV and YRTT areas. The InVEST model, which was developed by the Natural Capital Project to quantify and map the values of ecosystem services, was used in this study (Sharp et al., 2015).

The InVEST model is geographically explicit, using maps as inputs and producing maps as outputs. It returns results in either biophysical or economic terms. Due to its openness, it has been used widely by many studies and great results have been obtained (Fu et al., 2014; Hamel et al., 2015; Nelson et al., 2009; Posner et al., 2016; Su and Fu, 2013).

InVEST usually utilizes a production function to quantify and value ecosystem services. In this study, the InVEST model (version 3.3.1) sediment delivery ratio module was used to assess the influence of crop cover change on sediment retention services. Erosion and sediment retention are natural processes that govern the sediment concentration in streams. Sediment dynamics are mainly determined by climate conditions (especially the rainfall intensity), soil properties, topography, land cover, and human activities. Changes in land use and land management practices may dramatically modify the amount of sediment running off a catchment. The sediment delivery module is a geographically explicit model working at the spatial resolution of the input digital elevation model (DEM). For each cell, the model first computes the amount of eroded sediment, then the sediment delivery ratio (SDR), which is the proportion of soil loss actually reaching the catchment outlet.

The amount of annual soil loss for pixel $i$ is given by the revised universal soil loss equation:

$$
\text { usle }_{i}=R_{i} \cdot K_{i} \cdot L S_{i} \cdot C_{i} \cdot P_{i}
$$

where $u s l e_{i}$ denotes the amount of annual soil loss $\left(t o n \cdot h a^{-1} y r^{-1}\right), R_{i}$ denotes the rainfall erosivity $\left(M J \cdot m m(h a \cdot h r)^{-1}\right), K_{i}$ denotes the soil erodibility $\left(\right.$ ton $\left.\cdot h a \cdot h r(M J \cdot h a \cdot m m)^{-1}\right), L S_{i}$ denotes the slope length-gradient factor, $C_{i}$ denotes the crop-management factor, and $P_{i}$ denotes the support practice factor (Renard et al., 1997). The descriptions and sources of the inputs used in the InVEST model in this study are listed in Table 2.

The crop cover datasets reconstructed in this study were in a fractional format, whereas the land use/cover data required by the InVEST model needs to be in a binary format. Therefore, a transformation was performed. If the percentage of crop area in one grid was not less than $50 \%$, it was classified as crop. Otherwise, the grid was classified as other land use/cover types. A natural vegetation map was used to represent the vegetation types before human disturbances. It should be noted that rainfall erosivity was static in this study because of the lack of geographically explicit climate change data with a high resolution.

The support practice factor, $P$, accounts for the effects of contour plowing, strip-cropping, or terracing relative to straight-row farming up and down the slope. The cover-management 
factor, $C$, accounts for the specified crop and management required relative to the tillage of fallow land. The explicit values of these parameters for the study area were obtained from the Revised Universal Soil Loss Equation (RUSLE) handbook (Renard et al., 1997) and related studies (Wang et al., 2004) in the TP (Table 3).

Table 2 Inputs to the sediment delivery ratio module of the Integrated Valuation of Ecosystem Services and Trade-offs (InVEST) model (version 3.3.1) and data sources

\begin{tabular}{|c|c|c|}
\hline Input & Descriptions & Data sources \\
\hline $\begin{array}{l}\text { Digital } \\
\text { elevation } \\
\text { model (DEM) }\end{array}$ & $\begin{array}{l}\text { Digital elevation model, reflecting topography } \\
\text { properties }\end{array}$ & $\begin{array}{l}\text { Geospatial data cloud } \\
\text { (http://www.gscloud.cn/) }\end{array}$ \\
\hline $\mathrm{R}$ & $\begin{array}{l}\text { Rainfall erosivity index, reflecting climate prop- } \\
\text { erties }\end{array}$ & $\begin{array}{l}\text { National earth system science data } \\
\text { sharing infrastructure } \\
\text { (http://www.geodata.cn/) }\end{array}$ \\
\hline $\mathrm{K}$ & Soil erodibility index, reflecting soil properties & Liu et al., 2014a \\
\hline Watersheds & $\begin{array}{l}\text { A shapefile of polygons. The calculation is also } \\
\text { at watershed scale }\end{array}$ & $\begin{array}{l}\text { Institute of Geography, Chinese } \\
\text { Academy of Sciences, } 1997\end{array}$ \\
\hline $\mathrm{P}$ and $\mathrm{C}$ & $\begin{array}{l}\mathrm{P} \text { is the support practice factor and } \mathrm{C} \text { is } \\
\text { crop-management factor, reflecting vegetation } \\
\text { and anthropogenic factors }\end{array}$ & $\begin{array}{l}\text { RUSLE handbook (Renard et al., } \\
\text { 1997) and the TP related studies } \\
\text { (Wang et al., 2004) }\end{array}$ \\
\hline $\begin{array}{l}\text { Threshold flow } \\
\text { accumulation }\end{array}$ & $\begin{array}{l}\text { The number of upstream cells that must flow into } \\
\text { a cell before it is considered part of a stream }\end{array}$ & Default \\
\hline $\mathrm{k}_{\mathrm{b}}$ and $\mathrm{IC}_{0}$ & $\begin{array}{l}\text { Calibration parameters that determine the shape } \\
\text { of the relationship between hydrologic connec- } \\
\text { tivity and the SDR }\end{array}$ & Default \\
\hline $\mathrm{SDR}_{\max }$ & $\begin{array}{l}\text { The maximum sediment delivery ratio (SDR) } \\
\text { that a pixel can reach }\end{array}$ & Default \\
\hline
\end{tabular}

Table 3 Biophysical values of the cover-management factor $\mathrm{C}$ and support practice factor $\mathrm{P}$

\begin{tabular}{ccc}
\hline Land use/ cover categories & Cover-management factor C & Support practice factor P \\
\hline Cropland & 0.3 & 0.4 \\
Forestland & 0.003 & 0.2 \\
Shrubland & 0.02 & 0.2 \\
Grassland & 0.01 & 0.25 \\
Waterbody & 0 & 0.001 \\
Snow & 0 & 0.001 \\
Wetland & 0 & 0.001 \\
Built-ups & 0 & 0.01 \\
Unused land & 1 & 0.01 \\
\hline
\end{tabular}

\section{Results}

\subsection{Provincial cropland area changes for 1900-2000}

The changes of fractional cropland area (FCA) of Qinghai province, the TAR, and the whole study area for 1900-2000 can be divided into three phases: a slow increase phase during 1900-1950, a rapid increase phase during 1950-1980, and an overall steady phase during 
1980-2000 (Table 4).

Table 4 Cropland area in the Tibetan Plateau (TP) for 1900-2000. (Units: km².)

\begin{tabular}{cccccc}
\hline Province & 1900 & 1930 & 1950 & 1980 & 2000 \\
\hline Qinghai & $4272(0.597)$ & $4497(0.628)$ & $4527(0.632)$ & $6850(0.957)$ & $6875(0.960)$ \\
Tibet Autonomous Region & $1510(0.126)$ & $1590(0.132)$ & $1620(0.135)$ & $2350(0.196)$ & $2308(0.192)$ \\
Entire study area & $5782(0.301)$ & $6087(0.317)$ & $6147(0.320)$ & $9200(0.479)$ & $9183(0.478)$ \\
\hline
\end{tabular}

Note: The fractional cropland area (FCA) is provided in the brackets $(\%)$.

During 1900-1950, the FCA of the whole study area increased from $0.301 \%$ to $0.320 \%$, which is a very slow increase. During 1950-1980, the cropland area of the TP increased rapidly compared with $1900-1950$ and the FCA increased from $0.320 \%$ to $0.479 \%$ (Table 4), which can be attributed to a population increase and the reclamation activities of the Jiang Jieshi and Ma Bufang regimes. For the last two decades, the FCA of the whole study area remained stable. Similar cropland area increase patterns can be detected for Qinghai province and the TAR over the 20th century.

\subsection{Crop cover changes for $1900-2000$}

Crop cover in the TP for 1900, 1930, 1950, 1980, and 2000 is shown in Figure 2, with a particular focus on the YHRV and YRTT regions. It can be seen that land use activities intensified greatly in the YHRV and YRTT regions over the 20th century. Cropland expansion can be detected in the TP, but it was not obvious in the two selected regions because there has been human occupation of both regions since BP 3600 (Chen et al., 2015), with wide spread cultivation even in the 18th-19th centuries (Luo et al., 2014; Ryavec, 2001; Wang et al., 2015).

In 1900, the cropland was mainly distributed in the YHRV, especially in the Huangshui River Valley. While in the YRTT, the fractional cropland area of most grids was less than $10 \%$. Two decades later, the spatial pattern of crop cover was basically the same as in 1900 . By 1950, the land use had intensified slightly compared with the situation in 1900 . The fractional cropland area of most grids with a value of $1 \%-10 \%$ in 1900 increased to $11 \%-20 \%$ in 1950, especially in the YHRV. Overall, the spatial pattern of crop cover in the TP for 1900-1950 remained stable, while land use intensified slightly.

During 1950-1980, the land use intensified substantially in both the YHRV and YRTT. The fractional cropland area of most grids increased by more than $10 \%$, and in the YHRV and the YRTT the maximum values of the increase were $34 \%$ and $59 \%$, respectively. The most intensified regions in the YHRV were the Huangshui River, the Datong River, and the Yellow River valleys. The most intensified regions in the YRTT were the Nianchu River and the Lhasa River valleys. It can also be seen that close to the main streams, there was a greater rate of increase.

In the last 20 years of the 20th century, the spatial pattern remained basically stable because of the ecological protection policies implemented by the government.

\subsection{Sediment retention changes during 1900-2000}

The sediment export induced by crop cover changes in the YHRV was generally low during 
1900-2000 (Figure 3, Nos. a1-a5). The sediment export value of most grids were less than 11 ton/ha. Grids with relatively high values were only scattered in the Datong River and Huangshui River basins.
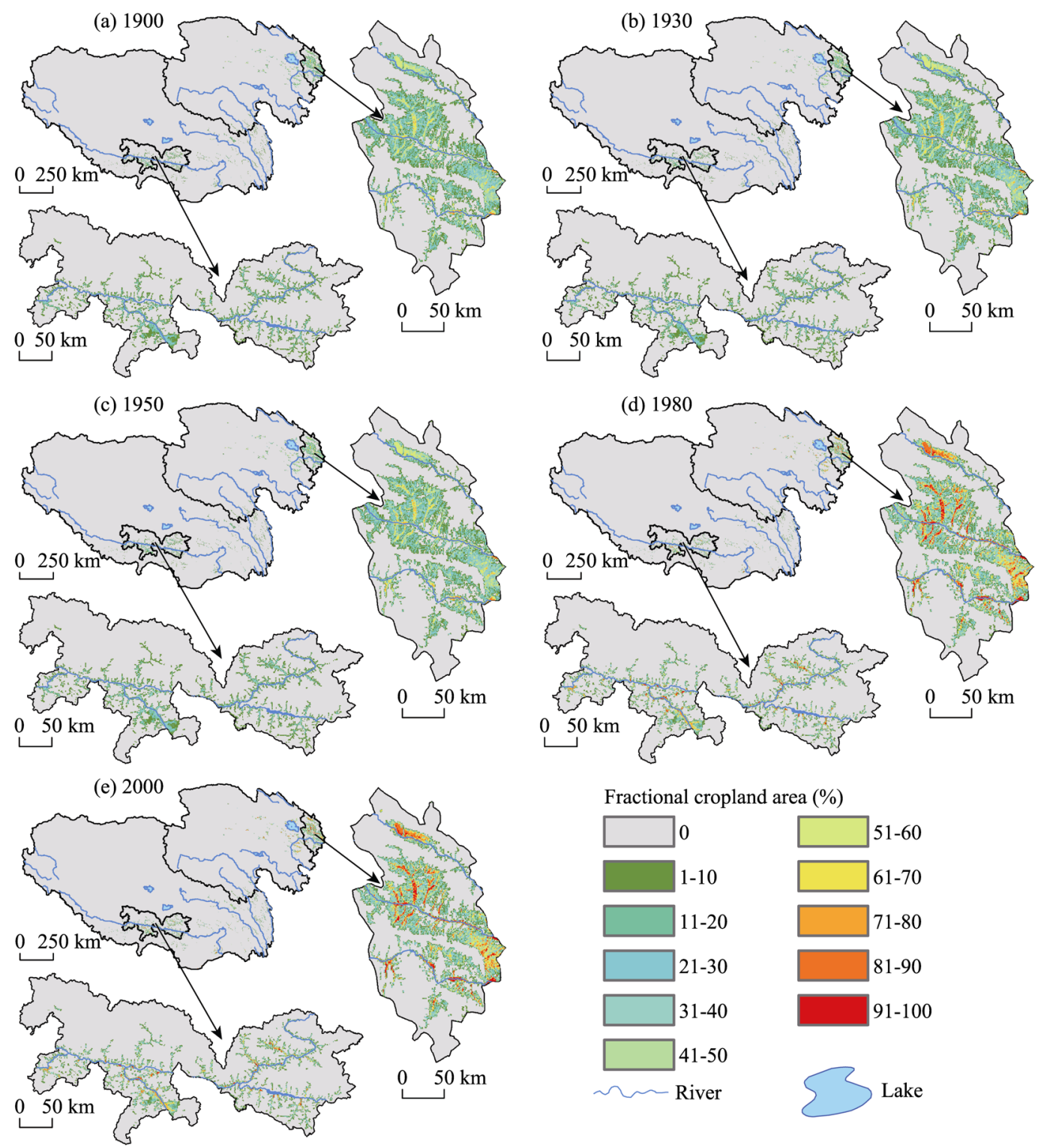

Figure 2 Crop cover of Qinghai Province and the Tibet Autonomous Region (TAR) with a resolution of $1 \times 1$ $\mathrm{km}$ for 1900, 1930, 1950, 1980, and 2000. The right subfigure is the Yellow River-Huangshui River Valley (YHRV) and the bottom subfigure is Yarlung Zangbo River and its two tributaries valley (YRTT).

In terms of the changes in sediment export over time, three stages were identified: a slight increase stage during 1900-1950, a rapid increase stage during 1950-1980, and a stable stage during 1980-2000. In the first stage, sediment export increased slightly and its spatial pattern remained stable over the first half of the 20th century. During 1950-1980, sediment export clearly increased, especially in Minhe autonomous county, with the amount in most 
grids increasing from less than 46 to $46-116$ ton/ha and then further increasing to 116-235 ton/ha. This increase was also detected in the middle reaches of the Datong River and Huangshui River basins. Over the last two decades, the value and spatial pattern of sediment exports remained approximately stable.

An increase in sediment export means a decrease in sediment retention services. In this study, the rainfall erosivity index was static, therefore any changes in sediment retention services could only result from changes in crop cover. During 1950-1980, the increase in the population and the intensification of land use activities led to a decrease in sediment retention services.
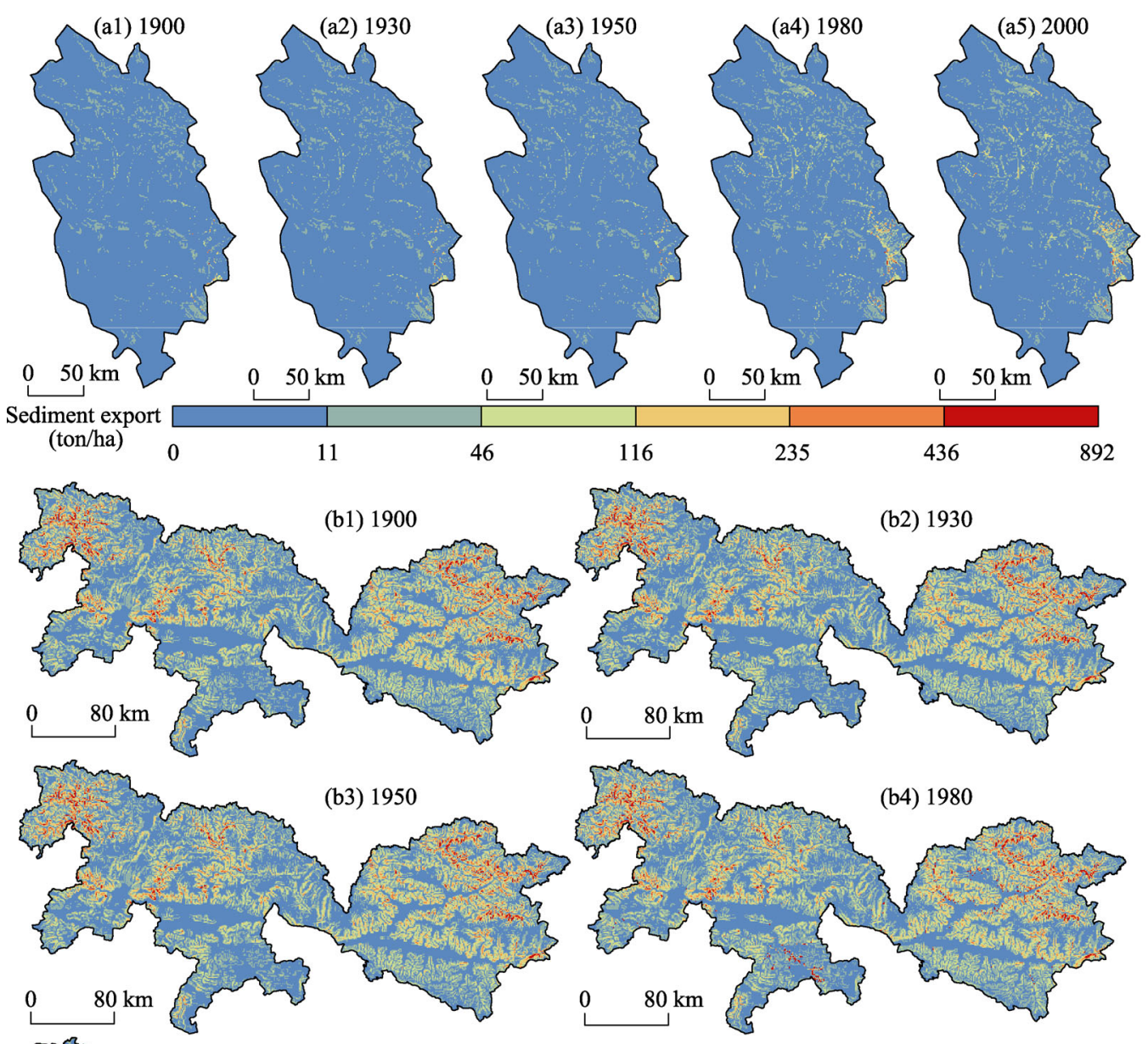

(b4) 1980

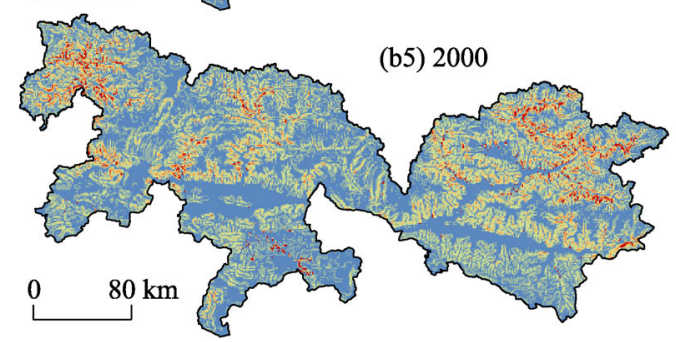

Sediment export (Ton/ha)

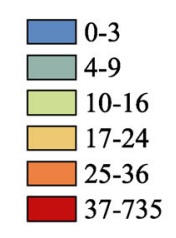

Figure 3 Sediment export induced by crop cover change in the Yellow River-Huangshui River Valley (YHRV) (Nos. a1-a5) and Yarlung Zangbo River and its two tributaries valley (YRTT) (Nos. b1-b5) for 1900, 1930, 1950, 1980 , and 2000 
It can be seen from the spatial patterns of sediment export in the YRTT that the sediment export north of the Yarlung Zangbo River was greater than the amount exported south of the river, especially in the Lhasa River valley, Nanmulin County, and Xietongmen County in the upper reaches of the Yarlung Zangbo River (Figure 3, Nos. b1-b5). During 1900-1950, sediment export increased slightly in the YRTT, with a similar change also observed in the YHRV. Subsequently, during 1950-1980, sediment export increased in regions where cropland increased, including the Nianchu River and the Lhasa River basins. In the Nianchu River basin, the sediment export increased from 0-3 ton/ha (4-9 ton/ha) to 25-36 ton/ha (37-735 ton/ha). In other words, the sediment retention services in the Nianchu River basin clearly decreased during 1950-1980. For other regions in the YRTT, no obvious changes were detected because changes in crop cover in these regions were not apparent. The spatial patterns of sediment export remained roughly stable during 1980-2000 in the YRTT.

\section{Discussion}

In this study, using a land suitability for cultivation model, the crop cover of the TP during the 20th century was reconstructed. Then, using the InVEST model (version 3.3.1) sediment delivery ratio module, the sediment retention services of the TP were assessed, with a focus on the YHRV and YRTT. We first compared our historical crop cover datasets with previous studies, and then the uncertainties and prospects were analyzed.

\subsection{Comparisons with previous studies}

Using a land suitability for cultivation model, Li et al. (2016) reconstructed the crop cover of China over the past 300 years at a resolution of $10 \times 10 \mathrm{~km}$. With some revisions to this method, Luo et al. (2014) reconstructed the crop cover of the YHRV in 1726 at a resolution of $2 \times 2 \mathrm{~km}$. In this study, we simplified the land suitability for cultivation model and improved the resolution of reconstruction. To evaluate the advances we made and the uncertainties of our study, we compared our results with those of Luo et al. (2014) and Li et al. (2016) respectively (Figure 4).
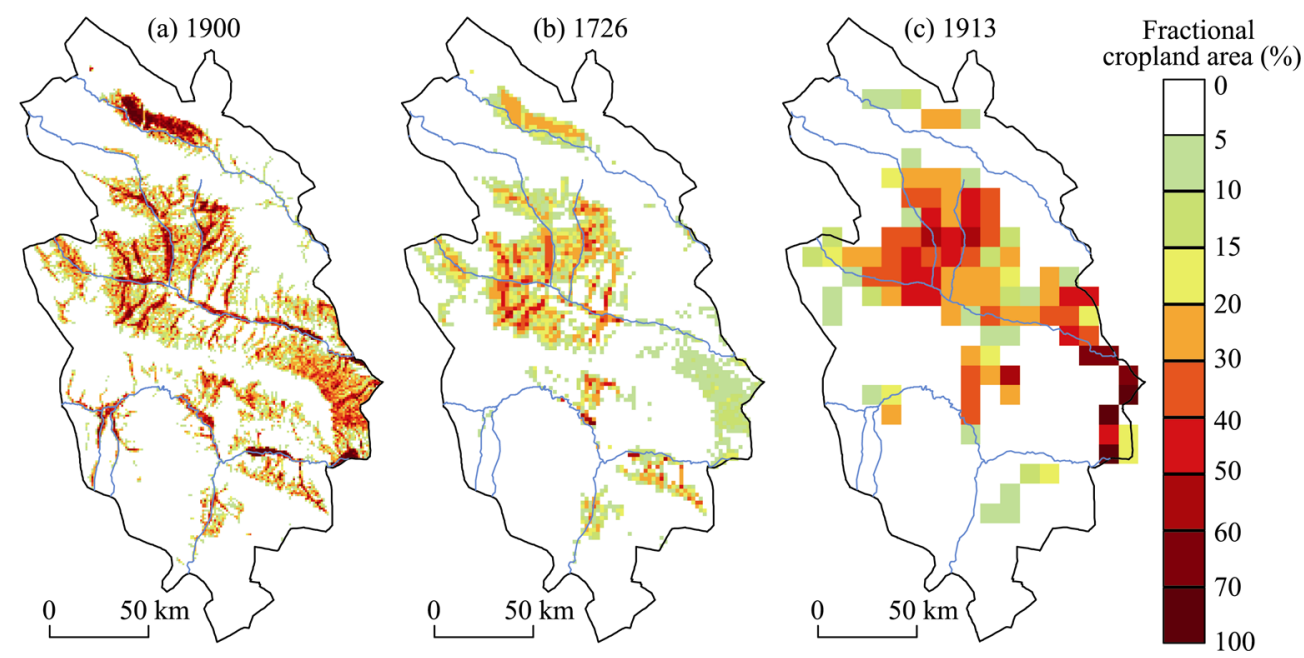

Figure 4 Comparison of spatial patterns among three datasets. (a) This study with a $1 \times 1 \mathrm{~km}$ resolution; (b) Luo et al. (2014) with a $2 \times 2 \mathrm{~km}$ resolution; (c) Li et al. (2016) with a $10 \times 10 \mathrm{~km}$ resolution 
Overall, the spatial patterns of the three studies were similar. All of them showed that cropland was mainly distributed in the Huangshui River, the Yellow River, and the Datong River basins (Figure 4). However, a closer examination indicated some discrepancies. For example, a lower land use intensity in the Yellow River and the Datong River basins was reported by Li et al. (2016) than the intensity found in the present study and in Luo et al. (2014). Further comparisons were therefore necessary. However, the resolutions and time periods of the three studies were different, so a pixel to pixel quantitative comparison was not possible. Therefore, we calculated the percentage cropland area in each elevation and slope interval for the three datasets and made an approximate comparison (Table 5).

It can be seen that the results of this study were basically consistent with those in datasets of Luo et al. (2014) and Li et al. (2016). Among the three datasets, the percentage cropland area was similar at each slope or elevation interval. Cropland was mainly distributed in regions with a slope within the intervals of $\leq 2^{\circ}, 2^{\circ}-6^{\circ}$, and $6^{\circ}-15^{\circ}$, and in regions with an elevation ranging from $2-3 \mathrm{~km}$. Regardless of elevation or slope, the percentage cropland area in each interval in this study and Luo et al. (2014) was similar. This may be because the spatial scale of the Li et al. (2016) dataset was $10 \mathrm{~km}$, which is very coarse compared with the $1 \mathrm{~km}$ dataset used in this study and the $2 \mathrm{~km}$ dataset used in Luo et al. (2014). As a national scale dataset, Li et al. (2016) paid more attention to national than local scale reconstruction.

In terms of the model factors and inputs (Table 5), only two factors were considered in this study, whereas in the models used by Luo et al. (2014) and Li et al. (2016), four and three factors were used, respectively. As the third pole of the world, the TP is a remote region of China and there is limited geographical data available. Historical population and climate data in a geographically explicit format are difficult to obtain, which limits the application of models of Luo et al. (2014) and Li et al. (2016). The input cropland area of the present study was at the provincial level, whereas in Luo et al. (2014) a county level input was used. Therefore, the simplified model used in this study has a broader potential for application in the TP.

Table 5 A comparison of the inputs, methods, and results among the three datasets

\begin{tabular}{|c|c|c|c|c|c|c|c|c|c|c|c|}
\hline \multirow[t]{2}{*}{ Reconstruction } & \multirow[t]{2}{*}{$\begin{array}{l}\text { Resolution } \\
\text { of input }\end{array}$} & \multirow[t]{2}{*}{$\begin{array}{l}\text { Factors } \\
\text { considered }\end{array}$} & \multirow[t]{2}{*}{ Resolution } & \multicolumn{4}{|c|}{$\begin{array}{l}\text { The percentage cropland area } \\
\text { in each slope interval }\left(^{\circ}\right)\end{array}$} & \multicolumn{4}{|c|}{$\begin{array}{l}\text { The percentage crop- } \\
\text { land area in each eleva- } \\
\text { tion interval }(\mathrm{km})\end{array}$} \\
\hline & & & & $\leqslant 2$ & $2-6$ & $6-15$ & $>15$ & $\leqslant 2$ & $2-3$ & $3-4$ & $>4$ \\
\hline This study & Province & Elevation, slope & $1 \mathrm{~km}$ & 24.1 & 60.7 & 15.0 & 0.1 & 8.3 & 79.2 & 12.5 & 0.0 \\
\hline Luo et al. (2014) & County & $\begin{array}{l}\text { Elevation, slope, } \\
\text { climate, population }\end{array}$ & $2 \mathrm{~km}$ & 23.0 & 62.1 & 14.8 & 0.2 & 3.2 & 85.6 & 11.2 & 0.0 \\
\hline Li et al. (2016) & Province & $\begin{array}{l}\text { Elevation, slope, } \\
\text { climate }\end{array}$ & $10 \mathrm{~km}$ & 14.4 & 59.0 & 26.3 & 0.4 & 5.5 & 69.7 & 24.1 & 0.8 \\
\hline
\end{tabular}

\subsection{Uncertainties and prospects}

Studies concerning LUCC and its long term ecological effects in the TP are rare. Therefore, we reconstructed the crop cover of the TP for 1900-2000 and assessed its effects on sedi- 
ment retention services, which represents pioneering work in this field. The uncertainties and future prospects of this work have also been considered. First, because of the scarcity of information, an assumption that the per capita cropland area was constant was applied to the estimation of cropland area in the first half of the 20th century. Because agricultural technology has slowly improved over time, this assumption may have underestimated the cropland area, especially for the earlier part of the century. Thus, a reconstruction of cropland area in the TP that is based on historical documents is needed in future studies. Second, climate change was not considered in the land suitability for cultivation model used in this study due to the unavailability of spatially explicit climate data. However, over the past one hundred years, the climate has clearly changed in the TP (Liu and Chen, 2000). Thus, better crop cover datasets of the TP need to be obtained if this factor is considered in subsequent allocation models.

The sediment delivery ratio module of the InVEST model relies on the universal soil loss equation, which represents rill-inter-rill erosion only. While this feature is common to many models of land use management, three other sources of sediment may contribute to the total sediment budget: gully erosion, stream bank erosion, and mass erosion (de Vente et al., 2013). Therefore, the sediment yield predicted by the model is less than the observations in some places and this needs to be taken into consideration in different decision-making contexts.

Because the resources needed to conduct model calibration and testing are scare, the sediment results used in this study were not calibrated. Without calibration, the InVEST sediment model still provides relevant information for the assessment of ecosystem services, especially in the context of decisions that involve the ranking of sediment export areas, such as the spatial prioritization of conservation, development or restoration activities, and taking into account non-linear sediment responses to changes in land use.

\section{Conclusions}

The cropland areas of Qinghai province and the TAR for 1900, 1930, 1950, 1980, and 2000 were estimated. Using a land suitability for cultivation model, we then allocated provincial cropland areas into grids with a size of $1 \times 1 \mathrm{~km}$. Finally, the influence of land use changes on sediment retention services were then assessed using the InVEST model. The major conclusions were as follows. Over the 20th century, the cropland area clearly increased, and land use activities intensified substantially in the YHRV and YRTT of the TP during 1950-1980. For other periods of the century, the cropland area and crop cover have remained relatively stable. Under the influence of changes in crop cover, sediment export has increased rapidly in Minhe autonomous county of the YHRV and in the Nianchu River and Lhasa River basins of the YRTT. The sediment retention services have clearly decreased in these regions during 1950-1980 because of changes in crop cover.

Comparisons with previous studies indicated that the reconstructed crop cover datasets used in this study are reasonable and the simplified model used in this study has a broader potential application in the TP. Our results will be of use to decision makers for conservation planning in these sensitive regions of the Earth. 


\section{Acknowledgements}

We would like to express our appreciation to Dr. Liu Bintao (Institute of Mountain Hazards and Environment of CAS) who provided rainfall erosivity and soil erodibility indexes data for this study, and to experts who provided valuable suggestions for the proposal of this study, including Professors Fu Bojie (Research Center for Eco-Environmental Sciences, CAS), Leng Shuying (National Natural Science Foundation of China), Zheng Du, Li Xiubin, Xie Gaodi, He Fanneng, Lv Changhe and Xu Zengrang from IGSNRR, and to three anonymous reviewers for their good comments.

\section{References}

Cao Shuji, Ge Jianxiong, 2001. China Population History (Volume V: Qing Dynasty). Shanghai: Fudan University Press. (in Chinese)

Chen Fahu, Dong Guanghui, Zhang Dongju et al., 2015. Agriculture facilitated permanent human occupation of the Tibetan Plateau after 3600 BP. Science, 347(6219): 248-250.

Cui Xuefeng, Graf Hans-F, 2009. Recent land cover changes on the Tibetan Plateau: A review. Climatic Change, 94(1/2): 47-61.

De Brue H, Verstraeten G, 2014. Impact of the spatial and thematic resolution of Holocene anthropogenic land-cover scenarios on modeled soil erosion and sediment delivery rates. Holocene, 24(1): 67-77.

de Vente Joris, Poesen Jean, Verstraeten Gert et al., 2013. Predicting soil erosion and sediment yield at regional scales: Where do we stand? Earth-Science Reviews, 127: 16-29.

Dias L C P, Pimenta F M, Santos A B et al., 2016. Patterns of land use, extensification, and intensification of Brazilian agriculture. Global Change Biology, 22(8): 2887-2903.

Ellis Erle C, Kaplan Jed O, Fuller Dorian Q et al., 2013. Used planet: A global history. Proceedings of the National Academy of Sciences of the United States of America, 110(20): 7978-7985.

Feng Zhiming, Liu Baoqin, Yang Yanzhao, 2005. A study of the changing trend of Chinese cultivated land amount and data reconstructing: 1949-2003. Journal of Natural Resources, 20(1): 35-43. (in Chinese)

Foley Jonathan A, DeFries Ruth, Asner Gregory P et al., 2005. Global consequences of land use. Science, 309(5734): 570-574.

Frolking S, Qiu J J, Boles S et al., 2002. Combining remote sensing and ground census data to develop new maps of the distribution of rice agriculture in China. Global Biogeochemical Cycles, 16(4): 1091.

Fu B, Wang Y K, Xu P et al., 2014. Value of ecosystem hydropower service and its impact on the payment for ecosystem services. Science of the Total Environment, 472: 338-346.

Future Earth, 2014. Future Earth 2025 Vision. http://www.futureearth.org/media/futureearth-2025-vision.

Gaillard M J, Sugita S, Mazier F et al., 2010. Holocene land-cover reconstructions for studies on land cover-climate feedbacks. Climate of the Past, 6(4): 483-499.

Hamel Perrine, Chaplin-Kramer Rebecca, Sim Sarah et al., 2015. A new approach to modeling the sediment retention service (InVEST 3.0): Case study of the Cape Fear catchment, North Carolina, USA. Science of the Total Environment, 524-525: 166-177.

He Fanneng, Li Shicheng, Zhang Xuezhen, 2015. A spatially explicit reconstruction of forest cover in China over 1700-2000. Global and Planetary Change, 131: 73-81.

He Fanneng, Li Shicheng, Zhang Xuezhen et al., 2013. Comparisons of cropland area from multiple datasets over the past 300 years in the traditional cultivated region of China. Journal of Geographical Sciences, 23(6): 978-990.

Institute of Geography, Chinese Academy of Sciences, 1997. Atlas of the Tibetan Plateau. (in Chinese)

Jantz S M, Barker B, Brooks T M et al., 2015. Future habitat loss and extinctions driven by land-use change in biodiversity hotspots under four scenarios of climate-change mitigation. Conservation Biology, 29(4): 
$1122-1131$.

Jin Xiaobin, Pan Qian, Yang Xuhong et al., 2016. Reconstructing the historical spatial land use pattern for Jiangsu Province in mid-Qing Dynasty. Journal of Geographical Sciences, 26(12): 1689-1706.

Kaplan Jed O, Krumhardt Kristen M, Ellis Erle C et al., 2011. Holocene carbon emissions as a result of anthropogenic land cover change. Holocene, 21(5): 775-791.

Klein Goldewijk Kees, Beusen Arthur, van Drecht Gerard et al., 2011. The HYDE 3.1 spatially explicit database of human-induced global land-use change over the past 12,000 years. Global Ecology and Biogeography, 20(1): 73-86.

Klein Goldewijk Kees,Verburg Peter H, 2013. Uncertainties in global-scale reconstructions of historical land use: An illustration using the HYDE data set. Landscape Ecology, 28(5): 861-877.

Lehnert L W, Wesche K, Trachte K et al., 2016. Climate variability rather than overstocking causes recent large scale cover changes of Tibetan pastures. Scientific Reports, 6: 24367.

Leite Christiane C, Costa Marcos H, Soares-Filho Britaldo S et al., 2012. Historical land use change and associated carbon emissions in Brazil from 1940 to 1995. Global Biogeochemical Cycles, 26: GB2011.

Li Beibei, Fang Xiuqi, Ye Yu et al., 2010. Accuracy assessment of global historical cropland datasets based on regional reconstructed historical data: A case study in Northeast China. Science in China Series D: Earth Sciences, 53(11): 1689-1699.

Li Shicheng, He Fanneng, Zhang Xuezhen, 2016. A spatially explicit reconstruction of cropland cover in China from 1661 to 1996. Regional Environmental Change, 16(2): 417-428.

Li Shicheng, Zhang Yili, He Fanneng, 2015. Reconstruction of cropland distribution in Qinghai and Tibet for the past one hundred years and its spatiotemporal changes. Progress in Geography, 34(2): 197-206. (in Chinese)

Liu Bintao, Tao Heping, Shi Zhan et al., 2014a. Spatial distribution characteristics of soil erodibility K value in Qinghai-Tibet Plateau. Bulletin of Soil and Water Conservation, 34(4): 13-16. (in Chinese)

Liu Jiyuan, Kuang Wenhui, Zhang Zengxiang et al., 2014b. Spatiotemporal characteristics, patterns, and causes of land-use changes in China since the late 1980s. Journal of Geographical Sciences, 24(2): $195-210$.

Liu Jiyuan, Liu Mingliang, Tian Hanqin et al., 2005. Spatial and temporal patterns of China's cropland during 1990-2000: An analysis based on Landsat TM data. Remote Sensing of Environment, 98(4): $442-456$.

Liu Xiaodong, Chen Baode, 2000. Climatic warming in the Tibetan Plateau during recent decades. International Journal of Climatology, 20(14): 1729-1742.

Luo Jing, Zhang Yili, Liu Fenggui et al., 2014. Reconstruction of cropland spatial patterns for 1726 on Yellow River-Huangshui River Valley in northeast Qinghai-Tibet Plateau. Geographical Research, 33(7): 1285-1296. (in Chinese)

Miao Lijuan, Zhu Feng, He Bin et al., 2013. Synthesis of China's land use in the past 300 years. Global and Planetary Change, 100: 224-233.

Miao Lijuan, Zhu Feng, Sun Zhanli et al., 2016. China's land-use changes during the past 300 years: A historical perspective. International Journal of Environmental Research and Public Health, 13(9): 847.

Nelson Erik, Mendoza Guillermo, Regetz James et al., 2009. Modeling multiple ecosystem services, biodiversity conservation, commodity production, and tradeoffs at landscape scales. Frontiers in Ecology and the Environment, 7(1): 4-11.

Newbold T, Hudson L N, Hill S L L et al., 2015. Global effects of land use on local terrestrial biodiversity. Nature, 520(7545): 45-50.

Pan Tao, Wu Shaohong, Liu Yujie, 2015. Relative contributions of land use and climate change to water supply variations over Yellow River Source Area in Tibetan Plateau during the past three decades. PLoS One, 10(4): e0123793.

Posner S, Verutes G, Koh I et al., 2016. Global use of ecosystem service models. Ecosystem Services, 17: $131-141$. 
Ramankutty N, Foley J A, 1999. Estimating historical changes in global land cover: Croplands from 1700 to 1992. Global Biogeochemical Cycles, 13(4): 997-1027.

Renard K G, Foster G R, Weesies G A et al., 1997. Predicting Soil Erosion by Water: A Guide to Conservation Planning with the Revised Soil Loss Equation. (RUSLE). United States Department of Agriculture, Agriculture Handbook, No.703, 1-367.

Ryavec Karl, 2001. Land use/cover change in central Tibet, c. 1830-1990: Devising a GIS methodology to study a historical Tibetan land decree. Geographical Journal, 167(4): 342-357.

Sharp R, Tallis H T, Ricketts T H et al., 2015. InVEST 3.2.0 User's Guide. The Natural Capital Project, Stanford University, University of Minnesota, The Nature Conservancy, and World Wildlife Fund.

Simmons C T, Matthews H D, 2016. Assessing the implications of human land-use change for the transient climate response to cumulative carbon emissions. Environmental Research Letters, 11(3): 035001.

Smith M C, Singarayer J S, Valdes P J et al., 2016. The biogeophysical climatic impacts of anthropogenic land use change during the Holocene. Climate of the Past, 12(4): 923-941.

Sturck J, Schulp C J E,Verburg P H, 2015. Spatio-temporal dynamics of regulating ecosystem services in Europe: The role of past and future land use change. Applied Geography, 63: 121-135.

Su Changhong, Fu Bojie, 2013. Evolution of ecosystem services in the Chinese Loess Plateau under climatic and land use changes. Global and Planetary Change, 101: 119-128.

Sun Honglie, Zheng Du, Yao Tandong et al., 2012. Protection and construction of the national ecological security shelter zone on Tibetan Plateau. Acta Geographica Sinica, 67(1): 3-12. (in Chinese)

Wang Xiaodan, Zhong Xianghao, Fan Jianrong, 2004. Assessment and spatial distribution of sensitivity of soil erosion in Tibet. Journal of Geographical Sciences, 14(1): 41-46.

Wang Yukun, Tao Juanping, Liu Fenggui et al., 2015. Reconstruction of cropland spatial pattern in 1830 in the middle reaches of Yarlung Zangbo River Valley. Geographical Research, 34(12): 2355-2367. (in Chinese)

Wei Xueqiong, Ye Yu, Zhang Qian et al., 2016. Reconstruction of cropland change over the past 300 years in the Jing-Jin-Ji area, China. Regional Environmental Change, 16(7): 2097-2109.

Yang Xuhong, Jin Xiaobin, Du Xindong et al., 2016. Multi-agent model-based historical cropland spatial pattern reconstruction for 1661-1952, Shandong Province, China. Global and Planetary Change, 143: 175-188.

Ye Yu, Fang Xiuqi, Ren Yuyu et al., 2009. Cropland cover change in Northeast China during the past 300 years. Science in China Series D: Earth Sciences, 52(8): 1172-1182.

Ye Yu, Wei Xueqiong, Li Fan et al., 2015. Reconstruction of cropland cover changes in the Shandong Province over the past 300 years. Scientific Reports, 5: 13642.

Zhang Xuezhen, He Fanneng, Li Shicheng, 2013. Reconstructed cropland in the mid-eleventh century in the traditional agricultural area of China: Implications of comparisons among datasets. Regional Environmental Change, 13(5): 969-977.

Zhang Yili, Li Bingyuan, Zheng Du, 2002. A discussion on the boundary and area of the Tibetan Plateau in China. Geographical Research, 21(1): 1-8. (in Chinese)

Zorrilla-Miras P, Palomo I, Gomez-Baggethun E et al., 2014. Effects of land-use change on wetland ecosystem services: A case study in the Donana marshes (SW Spain). Landscape and Urban Planning, 122: $160-174$. 